\title{
E-Learning using Cyberinfrastructure
}

\author{
http://dx.doi.org/10.3991/ijet.v7i2.2001 \\ J.J.Walker ${ }^{1}$, S.Swaid ${ }^{2}$ and M.Mortazavi ${ }^{1}$ \\ ${ }^{1}$ University of Arkansas at Pine Bluff, Pine Bluff, USA \\ 2 Philander Smith College, Little Rock, USA
}

\begin{abstract}
Cyberinfrastructure has become a major defining force for America, because of its economic, social, and national importance. Over the last two decades, scientists within all sectors of Science, Technology, Engineering and Mathematics (STEM) have witnessed an explosive rise of cyberinfrastructure as a research tool; universities are utilizing this infrastructure and its applications as an integral part of scientific education. The Arkansas Minority Cyberinfrastructure Training, Education Consortium (AMCTEC), is a unique interdisciplinary cyberinfrastructure (CI) educational community within Arkansas to educate a majority minority student population, and faculty in cyberinfrastructure-oriented concepts, theories, practices, and principles within STEM at teaching-oriented Historically Black Colleges and Universities (HBCUs). The project focuses on developing the capacity of these institutions within three core areas as they relate to cyberinfrastructure elearning resources, (1) institutional faculty development (2) tangible cyber-based student activities (3) CI curriculum enhancement. This paper presents some of the strategies that have been successfully deployed by the universities involved in the project to institutionalize a renaissance in STEM education, e-learning at student-focused universities, through the sharing of resources and expertise to transform STEM education and research by injecting in cyberinfrastructure resources.
\end{abstract}

Index Terms-Cyberinfrastructure, E-learning, STEM, HBCU

\section{INTRODUCTION}

Cyberinfrastructure has become a major defining force for America, because of its economic, social, and national importance. Cyberinfrastructure has now taken its place along side of the nation's critical infrastructure food, water, transportation, and energy resources, which are the nation's nervous system. Over the last two decades, scientists within all sectors of STEM have witnessed an explosive rise of cyberinfrastructure as a research tool, and universities are utilizing the infrastructure and its applications as an integral part of scientific education. Numerous government agencies including the National Science Foundation (NSF), Department of Defense (DOD), Department of Energy (DOE), and Central Intelligence Agency (CIA) are leveraging this important infrastructure as a tool for scientific discoveries $[6,9,10]$. As this infrastructure has emerged as a central tool in the next scientific evolution of U.S. STEM rebirth, the U.S. has become aware of the urgent need to educate a workforce in all sectors of STEM to take full-advantage of this shared resource to ensure that the U.S. remains competitive in STEM research, education and scientific innovation $[8,11,12]$. The current CI capable STEM workforce does not reflect the unique di- versity of the U.S., many segments of the population have been left out of this new domain of research, and education. For example, the fastest grown segments of the U.S. population is women and minority groups, while they only comprise only a small percentage of the current CIcapable workforce, and are almost absent in most relevant educational fields which use CI tools such as highperformance computing, computational science, distributed visualization and modeling $[13,14]$.

By increasing the active participation of members of underrepresented groups in cyberinfrastructure related activities at two HBCUs within Arkansas, the University of Arkansas at Pine Bluff (UAPB) and Philander Smith College (PSC), by exploiting both local and national cyberinfrastructure resources. By engaging these traditionally underrepresented communities in this manner, we hope to form a community of practice around cyberinfrastructure resources at these various institutions to enable the sharing of resources and insights to improve each campuses direct involvement in CI-oriented activities in Arkansas, nationally to ensure that the future STEM workforce reflect the unique diversity of the U.S.

Traditional STEM (Science, Technology, Engineering and Mathematics) education at small teaching-oriented institutions especially in rural states such as Arkansas, suffer from a lack of cross-disciplinary endeavors within STEM. Teaching-oriented institutions, which produce over $40 \%$ of the STEM undergraduates in the nation. Historically Black Colleges and Universities (HBCUs) graduate over $30 \%$ of all the African Americans within STEM that enter industry $[1,2]$. However, these universities have been left on the sideline in the current cyberinfrastructurerevolution taking place within STEM [3, 4]. These universities often lack the resources, the research and collaborative infrastructure that are available at Tier-1 research universities [5, 6]. Factors, such as relatively high teaching loads of individual faculty members, results in faculty often not being able to engage in cross-disciplinary discourse on their campus and in collaborative endeavors with faculty at other institutions. This results in isolated departments and contributes to the perception among many that the unique, far-reaching research and educational issues which require cyberinfrastructure (CI) tools are the domain of Tier- 1 universities. In addition, these small universities typically have small faculty research communities, over-committed information technology (IT) staff, and diverse financial challenges resulting in an uphill battle when attempting to support faculty, student and campus engagement in cutting-edge research $[7,8]$.

This project presented in this paper seeks to overcome many of these challenges by expanding both the community of CI-enabled HBCUs within the state of Arkansas and the population of faculty and institutions participating 
in CyberInfrastructure-oriented research and education as a means of improving the diversity of the STEM workforce.

\section{CI COMMUNities OF PRACTICE}

Wenger's [15] theory of "community of practice" provides useful insights into why and how a community of practice focused on cyberinfrastructure should be successful. Wenger, McDermott, and Snyder [16] define communities of practice as "groups of people who share a concern, a set of problems, or a passion about a topic, and who deepen their knowledge and expertise in this area by interacting on an ongoing basis.” According to these authors, communities of practice operate as "social learning systems" where practitioners connect to solve problems, share ideas, set standards, build tools, and develop relationships with peers and stakeholders. Because they are inherently boundary-crossing entities, communities of practice are a particularly appropriate structural model for cross-agency and cross-sector collaborations within this domain. [14, 17-19].

\section{A. Arkansas CI Community of Practice}

The state of Arkansas has invested heavily into modernizing its educational resources for its public universities. The state has taken the first steps to implement a statewide cyberinfrastructure community. In 2005, Arkansas started the development of the Arkansas Research and Education Optical Network (ARE-ON), at a cost of 10 million dollars, which provides high-speed optical networking services to all four-year public universities within Arkansas, for research, education, telehealth services, and emergency preparedness. The state has structured cyberinfrastructure resources not as a cure all for the problems of improving its STEM workforce, but as a tool to significantly diminish STEM workforce shortage within the state, nationally in this arena if properly deployed in relation to impacting STEM education, research, and scientific rejuvenation. The state's infrastructure is designed to transcend the traditional boundaries of a rural state and isolated universities to help faculty, students on each campus to engage in practical scientific inquiry, evidence-based learning, and technological advancement. As the infrastructure has been deployed on each campus, the question that many minority universities within the state are faced with is how to utilize this new infrastructure to fulfill their traditional missions of educating underrepresented communities, faculty scholarship and service. The AMC-TEC project is designed to engage and motivate these historically underrepresented communities to participate in the ARE-ON infrastructure in meaningful ways that will lead to deliberate scholarly cyberinfrastructureoriented research, and education. The project has formed a community of practice around the ARE-ON infrastructure, as well as national resources.

\section{$B$. Arkansas's HBCUs \& Cyberinfrastructure}

The University of Arkansas at Pine Bluff is currently using cyberinfrastructure-oriented technologies to encourage student, faculty interaction inside, outside of the classroom, and to promote student peer interaction in scientific applications. For example, all annual evaluations of faculty include a component on the integration and usage of interdisciplinary technologies in their courses. Also, Biology, Mathematical Sciences \& Technology, departments,
Computer Science Unit have recently developed a computational science based curriculum as a component of their existing programs. The curriculum now includes an introductory bioinformatics course, which is designed to be open to all majors, team-taught by biology, computer science faculty members. It is the first team-taught course in either department. The course uses cyberinfrastructurebased models to demonstrate data-driven informatics and visualization models.

In addition, the Biology, Chemistry \& Physics, Mathematical Sciences \& Technology departments within the College of Arts \& Sciences are in the early development stages of creating a cyberinfrastructure-based curriculum, which integrates in aspects of high-performance computing, and visualization into existing STEM courses. The intent of this new curriculum is to incorporate practical technologies, and computing principles within STEM courses, which will enable a majority minority student population to examine existing problems within their respective disciplines in innovative and unique ways. By integrating the theoretical and practical components of their field, students will be more motivated, resulting in increased student retention and interest in their respective STEM areas.

The Computer Science Unit at UAPB is also working with the Social \& Behavioral Sciences and English departments respectively to develop a curriculum in informatics that cuts across disciplinary boundaries to educate students in the computational character of the scientific analysis of humanity based artifacts such as painting and books. The new course will cover the storage, retrieval, and analysis of scientific data, the representation of scientific models and their use for prediction and explanation, the forms of communication and interaction that support communities, and the mechanisms that underlie scientific creativity and discovery within their field when combined with computing.

The university has also undertaken a substantial investment in STEM education redesign, by creating the STEM Academy funded through the NSF HBCU-UP program (award \#0929092 ) program. The academy currently has 150 STEM students enrolled. In addition, the university has also been awarded funding through NSF, for theArkansas Alliance for Minority Participation (ARKLSAMP) in STEM Careers (award \# 0802676), which is part of the STEM Academy. In addition, the university has also received funding from NSF, as part of the Collaborative Research: Cyberinfrastructure for Transformational Scientific Discovery in Arkansas and West Virginia (CITrain), (award \# 0918970) the project is designed to increase cyberinfrastructure research activities among eight universities in Arkansas and West Virginia. This project has led to a campus wide campaign to increase the role of cyberinfrastructure resources in STEM education and research.

Philander Smith College is Arkansas's oldest private HBCU. A privately supported, four-year liberal arts college is established in 1877. Currently, the Division of Natural and Physical Sciences is pursuing remedies to improve STEM education, students’ enrollment, academic performance and thereby students retention by using key funding initiatives. Among these initiatives are: (i) National Science Foundation's Historically Black Colleges and Universities - Undergraduate Program (HBCUUP)(NSF Grant 0411562, June 2004); (ii) the National 
Science Foundation's Louis Stokes Alliance for Minority Participation Program (LAMP) (award \# 0802676), have a broad goal of increasing the number of minorities in STEM. These projects aims onto: (i) Improving the readiness of High School Students in the area of STEM through the use of tutoring sessions and activity based learning (Pre-College Academic Year Program - HBCUUP) and college-level readiness (Summer Bridge Program - AMP, HBCU-UP); (ii) Providing research opportunities for junior and senior level students in STEM (Student Inspired Research Technology Summer Enrichment Program - HBCU-UP). Philander Smith College utilizes CIbased technologies to improve learning virtual environments, improve faculty-student communications and enable student-student collaborations. More specifically, the Division of Natural and Physical Sciences incorporating CI-based tools in education delivery and monitor such usage via faculty evaluations and students satisfactions surveys.

\section{CONCLUSION}

This paper outlines the efforts of the Arkansas Cyberinfrastructure Minority Training, Education Consortium (AMC-TEC) project to create a community of learners composed of a majority minority student population, and STEM faculty to address the national challenge of engaging an underrepresented population within STEM to utilize cyberinfrastructure research, and educational resources. The magnitude of the challenge that the U.S. faces with respect to ensuring that it retains its intellectual capacity within STEM research and innovation through the production of a workforce that is capable of serious science using both local, national and international cyberinfrastructure resources requires all capable individuals within STEM to take an active role in the intellectual discourse. This paper offers a replicable approach to increasing the participation of historically underrepresented communities and regions within cyberinfrastructureoriented research and education. The project achieves its goals by partnering mature cyberinfrastructure communities, local resources to inject cyberinfrastructure-oriented materials into existing curriculum and to expand the expertise of faculty with practical skills at HBCUs in Arkansas.

\section{REFERENCES}

[1] J. Pearce and M. Nakazawa, "The funnel that grew our cis major in the cs desert," presented at the Proceedings of the 39th SIGCSE technical symposium on Computer science education, Portland, OR, USA, 2008. http://dx.doi.org/10.1145/1352135.1352304

[2] L. Carter, "Why students with an apparent aptitude for computer science don't choose to major in computer science," presented at the Proceedings of the 37th SIGCSE technical symposium on Computer science education, Houston, Texas, USA, 2006. http://dx.doi.org/10.1145/1121341.1121352

[3] S. M. Sadjadi, S. Chen, S. Graham, S. Luis, Y. Deng, B. Furht, P. Martinez, N. Bowen, and J. Caraballo, "PIRE: a global living laboratory for cyberinfrastructure application enablement," presented at the The Fifth Richard Tapia Celebration of Diversity in Computing Conference: Intellect, Initiatives, Insight, and Innovations, Portland, Oregon, 2009.

[4] A. L. Bement, "Cyberinfrastructure: The Second Revolution," Chronicle of Higher Education, vol. 53, 2007.

[5] S. C. Simms, C. A. Stewart, and S. D. McCaulay, "Cyberinfrastructure resources for U.S. Scholarship: the TeraGrid," presented at the Proceedings of the 36th annual ACM SIGUCCS conference on User services conference, Portland, OR, USA, 2008. http://dx.doi.org/10.1145/1449956.1450057

[6] M. Abudiab and A. M. Mahdy, "Diversity of cyberinfrastructure: an opportunity for enhanced education and research," J. Comput. Small Coll., vol. 23, pp. 279-285, 2008.

[7] G. Almes, J. Cummings, J. P. Birnholtz, I. Foster, T. Hey, and B. Spencer, "CSCW and cyberinfrastructure: opportunities and challenges," presented at the Proceedings of the 2004 ACM conference on Computer supported cooperative work, Chicago, Illinois, USA, 2004.

[8] J. Connolly and E. Landwehr, "Cyberinfrastructure and education," presented at the Proceedings of the 2006 ACM/IEEE conference on Supercomputing, Tampa, Florida, 2006. http://dx.doi.org/10.1145/1188455.1188477

[9] C. P. Lee, P. Dourish, and G. Mark, "The human infrastructure of cyberinfrastructure," presented at the Proceedings of the 2006 20th anniversary conference on Computer supported cooperative work, Banff, Alberta, Canada, 2006. http://dx.doi.org/10.1145/11465 $\underline{98.1146603}$

[10] D. E. Atkins, K. K. Droegemeier, S. I. Feldman, H. GarciaMolina, M. L. Klein, D. G. Messerschmitt, P. Messina, J. P. Ostriker, and M. H. Wright, "Revolutionizing Science and Engineering Through Cyberinfrastructure:Report of the National Science Foundation Blue-Ribbon Advisory Panel on Cyberinfrastructure," National Science Foundation, ARLINGTON, ReportJune 20, 2003 2003.

[11] N. Contractor and B. W. Hesse, "Cyberinfrastructure for public health," presented at the Proceedings of the 2006 international conference on Digital government research, San Diego, California, 2006. http://dx.doi.org/10.1145/1146598.1146603

[12] C. B. Simmons and L. L. Simmons, "Gaps in the computer science curriculum: an exploratory study of industry professionals," $J$. Comput. Small Coll., vol. 25, pp. 60-65, 2010.

[13] R. Anderson, R. Anderson, K. M. Davis, N. Linnell, C. Prince, and V. Razmov, "Supporting active learning and example based instruction with classroom technology," presented at the Proceedings of the 38th SIGCSE technical symposium on Computer science education, Covington, Kentucky, USA, 2007. http://dx.doi.org/10.1145/1227310.1227338

[14] E. F. Gehringer and C. S. Miller, "Student-generated activelearning exercises," presented at the Proceedings of the 40th ACM technical symposium on Computer science education, Chattanooga, TN, USA, 2009.

[15] E. Wenger, Communities of Practice Learning, Meaning, and Identity. New York City: Cambridge University Press, 1999.

[16] E. Wenger, R. McDermott, and W. M. Snyder, Cultivating Communities of Practice: A Guide to Managing Knowledge. Cambridge, MA: Harvard Business School Press, 2002.

[17] J. E. Urban, J. M. Heines, E. A. Fox, and H. G. Taylor, "Panel on revitalized undergraduate computing education," presented at the Proceedings of the 40th ACM technical symposium on Computer science education, Chattanooga, TN, USA, 2009. http://dx.doi.org/ $\underline{10.1145 / 1508865.1508893}$

[18] M. v. t. Hooft and K. Swan, Ubiquitous computing in education : invisible technology, visible impact. Mahwah, N.J.: Lawrence Erlbaum Associates, 2007.

[19] K. Hoganson, "Computer science curricula in a global competitive environment," J. Comput. Small Coll., vol. 20, pp. 168-177, 2004.

[20] A. Conklin, "The use of a collegiate cyber defense competition in information security education," presented at the Proceedings of the 2nd annual conference on Information security curriculum development, Kennesaw, Georgia, 2005. http://dx.doi.org/10.1145/ $\underline{1107622.1107627}$

\section{AUTHORS}

J.J Walker is an Assistant Professor of Computer Science, University of Arkansas at Pine Bluff, AR 71601 USA (e-mail: Walkerjj@uapb.edu).

S. Swaid, is an Assistant Professor of Computer Science, Philander Smith College, Little Rock, AR 72201 USA (e-mail: sswaid@philander.edu). 
SHORT PAPER

E-LEARNING USING CYBERINFRASTRUCTURE

M. Mortazvi is a Professor of Physics, University of Arkansas at Pine Bluff, Pine Bluff, AR 71601 USA (email: mortazavim@uapb.edu).

The Arkansas Cyberinfrastructure Minority Training, Education Consortium (AMC-TEC) project is funded through a CI-TEAM award \# 1041420, from the National Science Foundation. Received, 27 February 2012. Published as resubmitted by the authors 27 May 2012. 